\section{Digital dental photography. Part 7: extra-oral set-ups}

\author{
I. Ahmad'
}

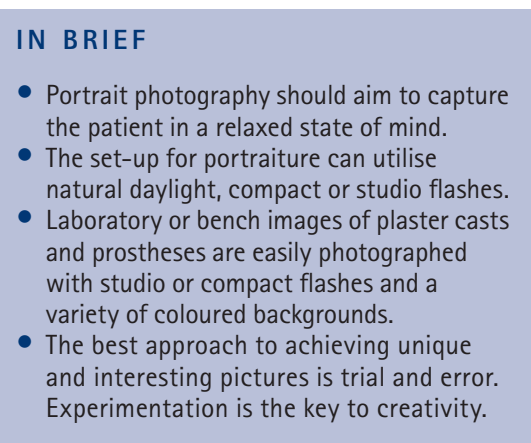

This part of our series specifically addresses extra-oral dental photography consisting of portraiture and dental laboratory pictures. Portraiture, which is achieved using three types of illumination, natural daylight, bi-lateral camera mounted flashes (as for intra-oral images) or studio flashes, can be further divided into full face and dento-facial compositions. These are necessary for various dental disciples including evaluation of aesthetics, orthodontics and oral surgery facial profile assessment. Dental laboratory photography includes documentation of plaster casts and indirect prostheses.

Extra-oral dental photography consists of portraiture and dental laboratory pictures. Portraiture can be further divided into full face and dento-facial compositions, which are necessary for various dental disciples including evaluation of aesthetics, orthodontics and oral surgery facial profile assessment. Dental laboratory photography includes documentation of plaster casts and indirect prostheses.

\section{PORTRAITURE}

Before describing set-ups for facial images, it is necessary to consider a few theoretical aspects about portraiture photography.

\section{FUNDAMENTALS OF DIGITAL DENTAL PHOTOGRAPHY}

1. Digital dental photography: an overview

2. Purposes and uses

3. Principles of digital photography

4. Choosing a camera and accessories

5. Lighting

6. Camera settings

7. Extra-oral set-ups

8. Intra-oral set-ups

9. Post-image capture processing

10. Printing, publishing and presentations

General Dental Practitioner, The Ridgeway Dental Surgery, 173 The Ridgeway, North Harrow, Middlesex, HA2 7DF

Correspondence to: Irfan Ahmad

Email: iahmadbds@aol.com

www.IrfanAhmedTRDS.co.uk

\section{Refereed Paper}

Accepted 15 November 2008

DOI: $10.1038 /$ sj.bdj.2009.667

${ }^{\oplus}$ British Dental Journal 2009; 207: 103-110

\section{Space}

The distance between the photographer (clinician) and the subject (patient) is termed the photographic space. However, the latter needs to be in context with other human spaces, ensuring that the patient feels comfortable, relaxed and at no time feels that his or her privacy is being invaded.

All animals, including humans, have a predefined territory in which they feel comfortable and at ease with their environment. This is a primitive survival instinct to guard against predators and potential danger. In the case of animals, if this space is violated, the reaction is either an imminent attack (defence), or fleeing (preservation). For humans, trespassing causes unease, tension or even rebuke. Human space is categorised into intimate, personal, social and public. Approximate ranges for these spaces are listed in Table 1 and diagrammatically shown in Figure 1.

The human spaces vary depending on personality, culture, context and age. Timid, shy or introverted individuals usually have a larger intimate space than the norm, while the opposite is true for vivacious and gregarious personalities, and in Eastern cultures closer proximity is permissible than would be possible with Western etiquettes. Also, the context in which a photograph is taken alters the distance of spaces. People at ceremonial occasions, such as weddings, allow greater approach than in a working or professional environment. Finally, age also determines how close one can approach without

\begin{tabular}{|c|c|}
\hline Space & Distance $(\mathrm{m})$ \\
\hline Intimate & 0 to 0.5 \\
\hline Personal & 0.5 to 1.5 \\
\hline Social & 1.5 to 3.25 \\
\hline Public & Beyond 3.25 \\
\hline
\end{tabular}

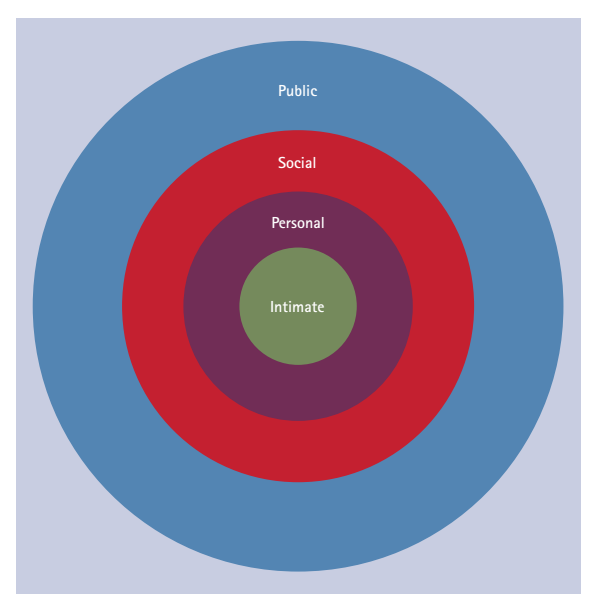

Fig. 1 Schematic diagram of human spaces

causing alarm or unease. Generally, children require greater personal space than adults.

The goal of the clinician is gauging the patient's personal space and respecting it at all times. This creates a relaxed ambience for both the operator and subject, yielding photographs that convey serenity rather than tension. A simple way to overcome a potential space barrier is using long focal length portrait lenses (greater than $100 \mathrm{~mm}$ ), which allow the 
photographer to 'virtually' intrude into the intimate or personal space, without agitating the subject.

\section{Relating}

Photographers relate to a subject in three ways: projection, introjection and confluence.

According to the Freudian concept of psychological defence mechanisms, projection is a means to alleviate personal anxieties. In an attempt to resolve personal conflicts, an individual attempts to project his inner feeling onto external entities such as the environment, people, art, music, etc. This allows the person to come to terms with his or her inner conflicts with the aim of achieving serenity and a pacifistic state of mind. Depending on a photographer's psychological make-up, his or her projection is usually manifested in the photographs they take. A familiar example is the contrived post-operative photograph after restoring the maxillary anterior teeth. Many clinicians request a female patient to apply lurid lipstick to increase the colour contrast between the lips and teeth. In these circumstances the red lipstick is the operator's projection onto the patient, conveying the clinician's sensual emotions.

Introjection is the opposite of projection, allowing the subject to reveal their inner essence and outer presence. In this situation the subject is conveying their personality, rather than having the operator's personality imposed on them. This type of photograph requires familiarity with the patient, achieving a sense of ease

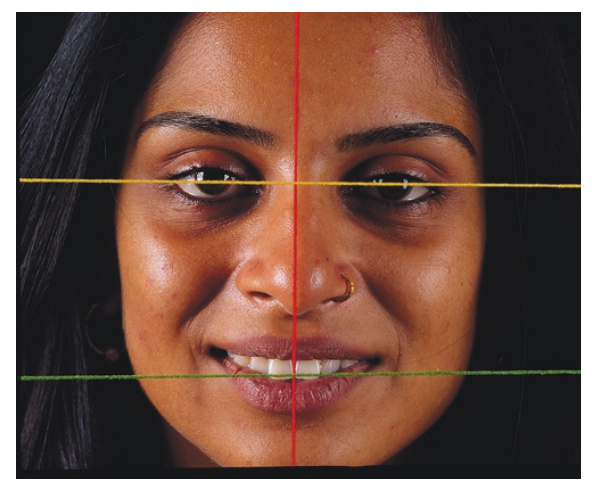

Fig. 2 A relaxed facial image is ideal for assessing the inclination of the incisal plane to the inter-pupillary line

with staff and the practice environment. A dental example is the classical relaxed smile, with the incisal plane of the maxillary incisor teeth parallel to the curvature of the lower lip.

Finally, confluence is when, for a fleeting moment, the photographer and subject unite (mentally) and are in unison with one another. This requires patience, dedication, and protracted perseverance. This type of image is probably the most challenging, and if achieved, conveys a transcendental quality that appeals to the inner psyche. The photograph elevates to a level that touches our inner subconscious level, having a profound and lasting impact.

To summarise, projection is 'going to the subject', introjection is 'letting the subject come to you' and confluence is 'achieving a one-ness'. As a general observation, advertising companies ubiquitously use projection images to sell products. A beautiful model is often depicted in proximity to the

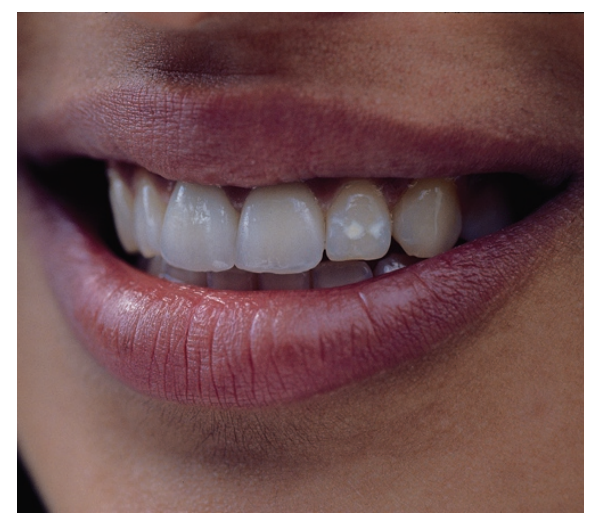

Fig. 3 A dento-facial image shows the teeth in relation to the surrounding lips

product, representing an elusive and desirable commodity. Introjection images are family gatherings and holiday snap shots, when people are relaxed with familiar company and surroundings. Lastly, confluence imagery is usually artistic in nature and the photograph becomes more than mere documentation, having a deeper meaning than that which is literally depicted.

When fabricating aesthetic anterior restorations, the appearance of which can be highly subjective, it is important to ascertain as much information as possible about patients' wishes, desires and their perception of themselves. Therefore, dental portraiture should avoid projection and encourage introjection imagery, allowing the patient to express their personality. For example, an introvert may be better suited for crowns that blend with the existing dentition, with cervical stains, cracks and characterisations. Conversely, the latter would be inappropriate for fashion conscious individuals who

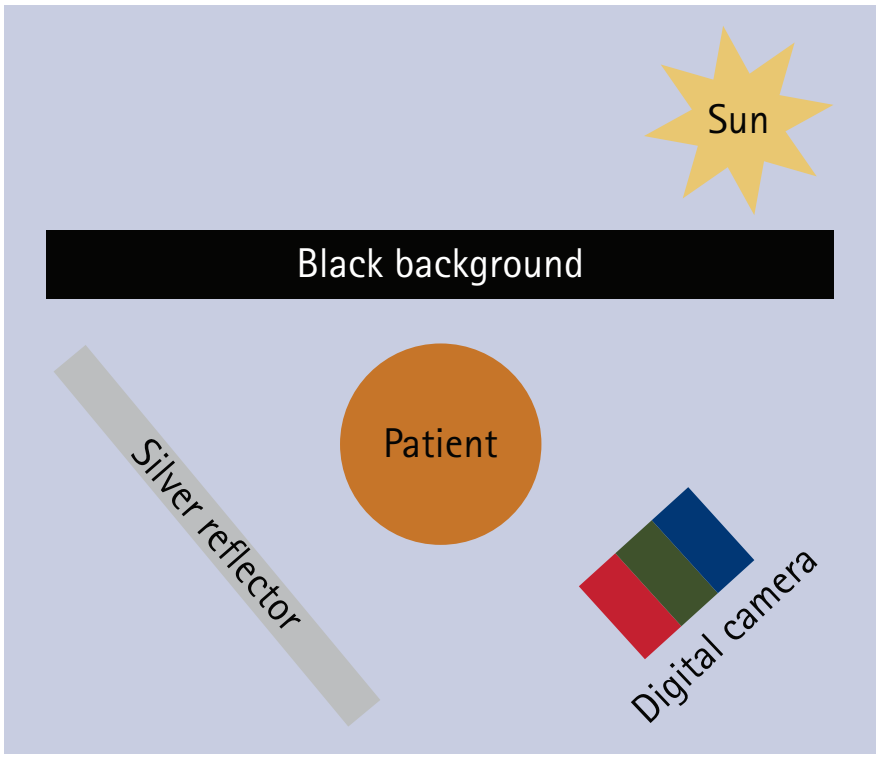

Fig. 4 Portrait set-up using natural daylight for illumination

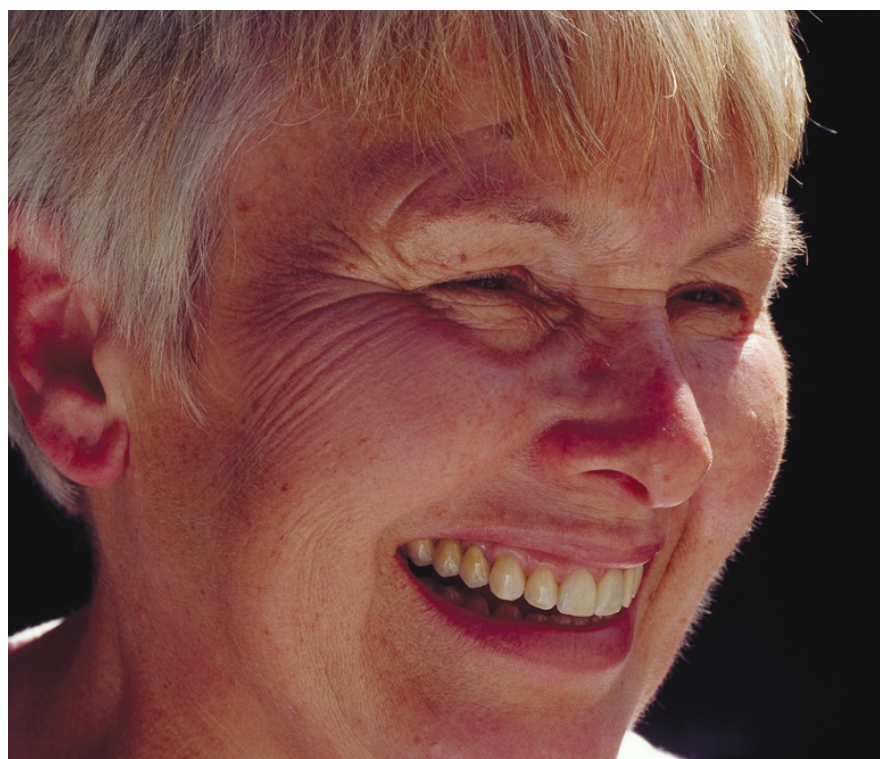

Fig. 5 Portrait using the set-up shown in Figure 4 


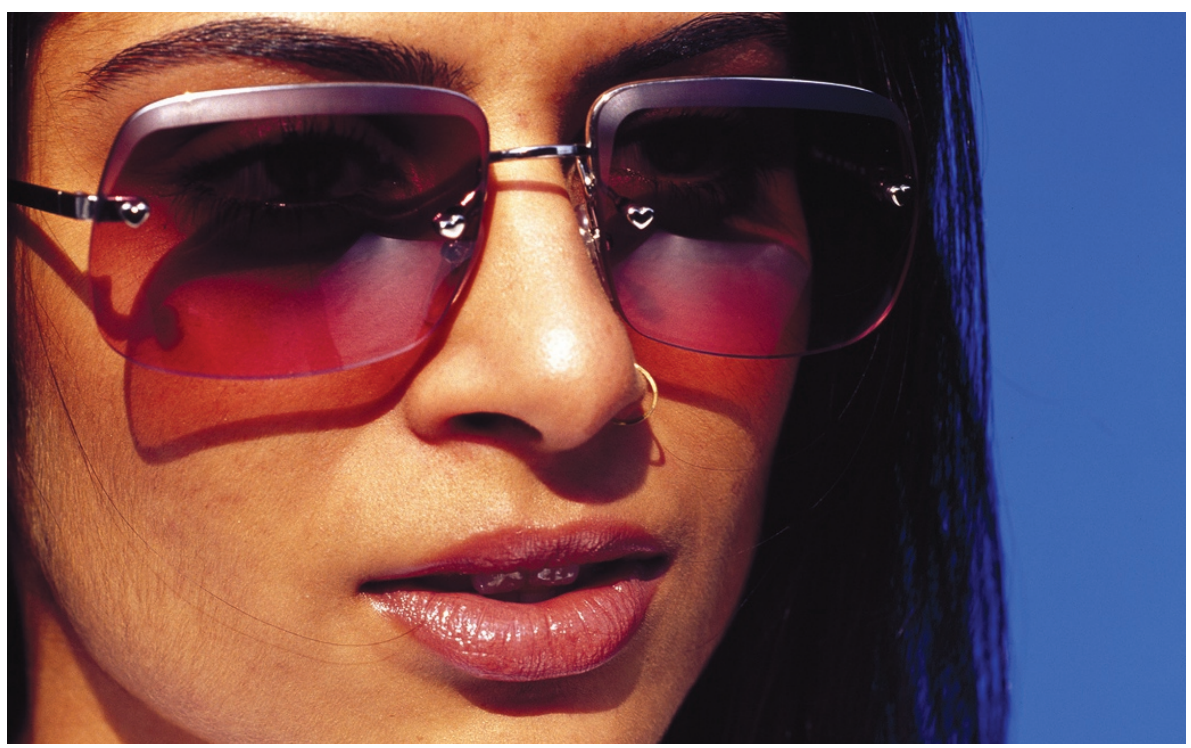

Fig. 6 Sunlight directed into a subject's face creates unflattering shadows that obscure facial features, especially when wearing spectacles

desire the 'bright, white, right look', and are ideal candidates for A1, or even B1, monochromatic restorations.

\section{DENTAL PORTRAITURE SET-UPS}

The set-up for facial or portraits can be achieved using three types of illumination, natural daylight, bi-lateral camera mounted flashes (as for intra-oral images) or studio flashes. The types of pictures required depend on the intended facial assessment. Some suggestions are as follows:

1. Frontal facial at rest (for example, assessing persona of patient)

2. Frontal facial during a relaxed smile (for example, assessing incisal plane relationship to the inter-pupillary line) - Figure 2

3. Frontal facial with exaggerated smile (for example, assessing degree of maxillary gingival exposure)

4. Profile at rest (for example, orthodontic assessment, lip positions)

5. Profile during a relaxed smile (assessing inclination of maxillary incisors)

6. Profile with exaggerated smile

7. Dento-facial images (framing only lips and teeth) with same poses as for full frontal facial pictures - Figure 3.

\section{Natural daylight set-up}

Although unpredictable, if judicially manipulated, natural daylight can be economical and a superb illumination for facial images. To ensure correct exposure and white balance, it is worth taking a test shot with an $18 \%$ grey card as described in Part 6. ${ }^{1}$ The set-up is very simple, requiring few items (Figs 4-5):

1. Cloth or card as a background, either black or colour of choice

2. Card or cloth reflectors, white, silver or gold (purchased from photographic retailer or art card cut to size $\left(1 \mathrm{~m}^{2}\right)$

3. Tripod for using slower shutter speeds or wider apertures if light is low due to a cloudy day.

On an overcast day, the only item required is a cloth or card for the background, which can be suspended or hand-held by the dental assistant. If taking pictures in sunlight, it is crucial that the sun is behind or to the side of the patient. Pictures taken with the sunlight directly above, or in front of the patient causes unflattering shadows by the eyebrows, nose and lips that obscure the facial features (Fig. 6). This is also true for patients who wear spectacles, which can hide the eyes and pupils, which are crucial for aesthetic assessment. The simple set-up shown in Figure 4 uses a black background and a silver reflector for bouncing sunlight onto the patient's face. This type of set-up is very flattering since it 'irons out' wrinkles by soft illumination, but care is necessary not to cause squinting by inadvertently directing light into the eyes from the reflector. Altering the angle and type of reflector changes the mood of the picture, for example a smooth white reflector produces subtle illumination, while silver is more

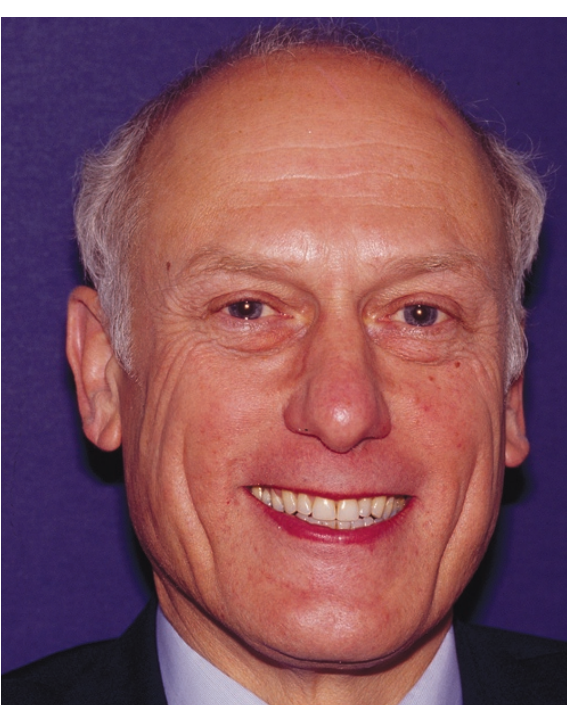

Fig. 7 Camera mounted compact flashes create annoying shadows behind the patient's head with coloured or textured backgrounds

vibrant and punchy and gold creates a warmer ambience.

\section{Bi-lateral camera mounted flashes set-up}

The second option is using cameramounted flashes such as ring or bilateral flashes. The advantages of this set-up are convenience and expedience, as well as being economical and space saving. However, the intensity of ring and bilateral flashes is usually insufficient for illuminating the face. Using wider apertures and slower speeds may obtain correct exposure, but the quality of illumination is uniform, which is equivalent to shining car headlights in someone's face. The resulting picture is flat and dull with poor detail and reduced dynamic range. Furthermore, with a coloured background, annoying shadows are visible behind the subject's head (Fig. 7). This set-up is only recommended for convenience, but is not advisable for quality facial images.

\section{Studio flash set-ups}

Studio flashes are the ideal, predictable and widely used for high quality portraits. An area of approximately $4 \mathrm{~m}^{2}$ should be allocated for a studio set-up, which can either be a separate room or part of the surgery, waiting room or reception area. The inventory for a simple studio set-up consists of the following:

1. Two or three electronic studio flashes

2. Flash soft boxes or reflective umbrellas 


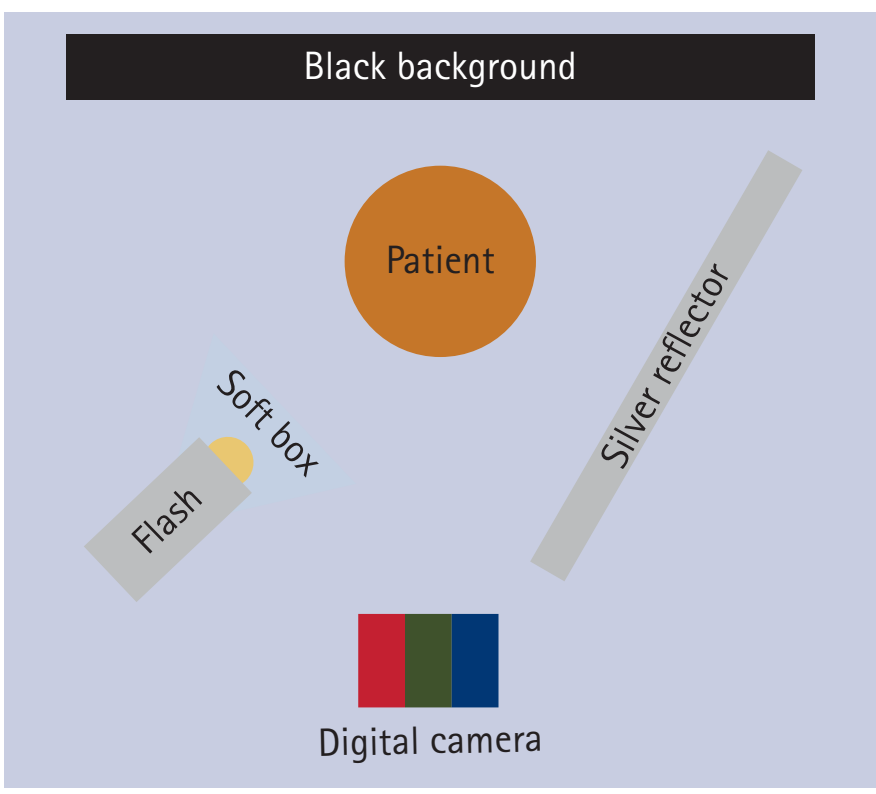

Fig. 8 Studio set-up 1: black background, one flash and one reflector

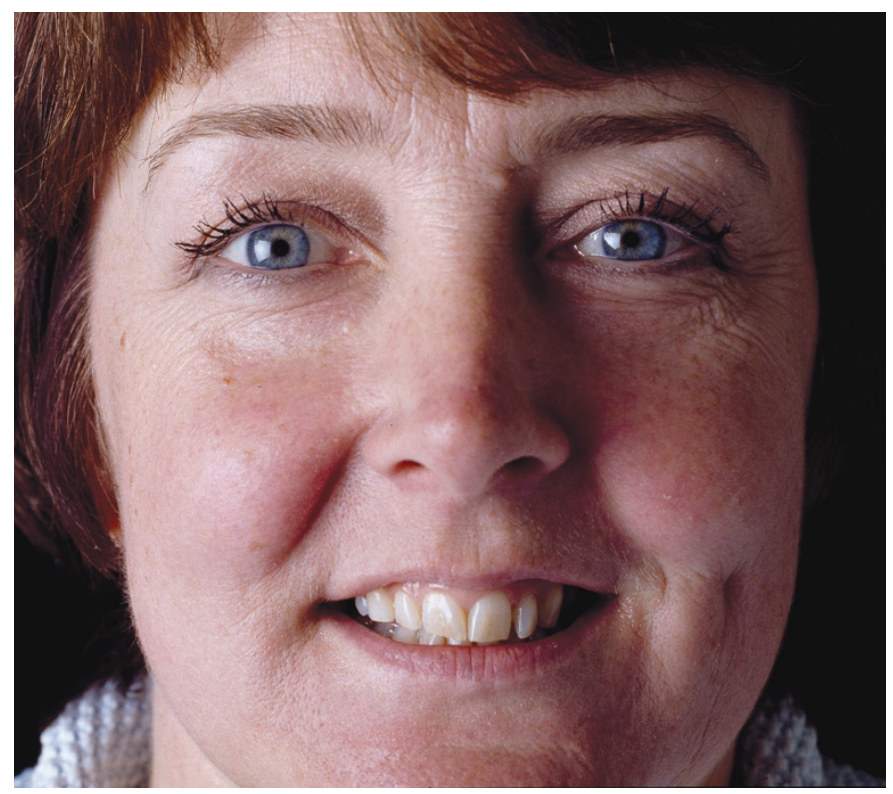

Fig. 9 Image using set-up shown in Figure 8
3. Light modifying flash attachments, for example barn doors, spot cones, mesh grids

4. Selection of reflectors, for example white, silver and gold

5. Coloured fabrics or cards for backdrops.

The choice of flashes depends on the budget, but relatively inexpensive units are available from numerous manufacturers. Using naked flashes produces harsh lighting that usually requires muting, either by using soft boxes, reflective umbrellas or attachments such as meshes that fit directly onto the flash heads. In addition, various reflectors and backgrounds are necessary to complete the armamentarium. For constantly predictable facial shots, the set-ups below should suffice. However, to be more adventurous, experimentation with different attachments, reflectors, backgrounds, etc can yield creative and unique results.

\section{Studio set-up 1: black background, one flash and one reflector}

This is the simplest studio set-up, with a black background that can be used for standard portrait images (Figs 8-9). A black fabric (eg velvet) background absorbs light from the flash and reflector and therefore conceals all shadows. The choice of reflectors depends on the desired mood, and can be white, silver or gold. The flash is covered with a soft box, while the reflector softens shadows on the opposite side, but does not eliminate them as in set-up 2 below.

Studio set-up 2:

\section{black background, two flashes}

Having two bi-lateral studio flashes totally eliminates shadows rather than softening them as in set-up 1. Both flashes have soft boxes or reflective umbrellas to mute the light output (Figs 10-11).

\section{Studio set-up 3: coloured background, two flashes and one reflector}

This set-up uses a coloured instead of a black background. If set-up 1 were used with a coloured background, unwanted shadows behind the patient would be visible. For this reason a second flash is used to illuminate the background separately. This also has the effect of creating depth and a three dimensional effect by separating the subject from its background (Figs 12-13).

\section{Studio set-up 4: \\ black background, one flash}

For profile images, a single flash with a soft box or other attachment is used as a unidirectional light to illuminate the face (Figs 14-15).

\section{Studio set-up 5: coloured background, two flashes}

This is identical to set-up 4, except a coloured background substitutes the black backdrop. The arrangement is particularly useful for dento-facial profile and lateral images (Figs 16-17).

\section{DENTAL LABORATORY SET-UPS}

The types of dental laboratory pictures are limitless, ranging from nuances within artificial crowns to showing techniques, instruments and equipment. Some examples include documenting pre-operative casts, diagnostic wax-up and surgical stent for guiding implant placement for the patient in Figures 18-20. Similarly, the patient in Figures 21-23 required veneers for the mandibular teeth. After the wax-up, a transparent vacuum stent based on the wax-up was delivered as a template for fabricating chairside temporary veneers.

Is impossible to show every type of possible set-up, and instead a few simple setups are described which can be adapted and tailored to specific needs depending on the items to be photographed.

The most frequently photographed items in the dental laboratory are plaster casts. These can be of both maxillary and mandibular arches, only one arch, a few teeth, and with or without artificial prostheses. Plaster casts are relatively bland, usually monochromatic and visually boring. One method to add interest is incorporating different coloured or textured backgrounds, or trans-illumination to visualise characteristics within a ceramic restoration. Using different coloured cards enhances colour contrast between the plaster cast and coloured background. Two types of lighting set-up are possible. The first is the studio set-up described for portraiture. The only difference is that a bench or 


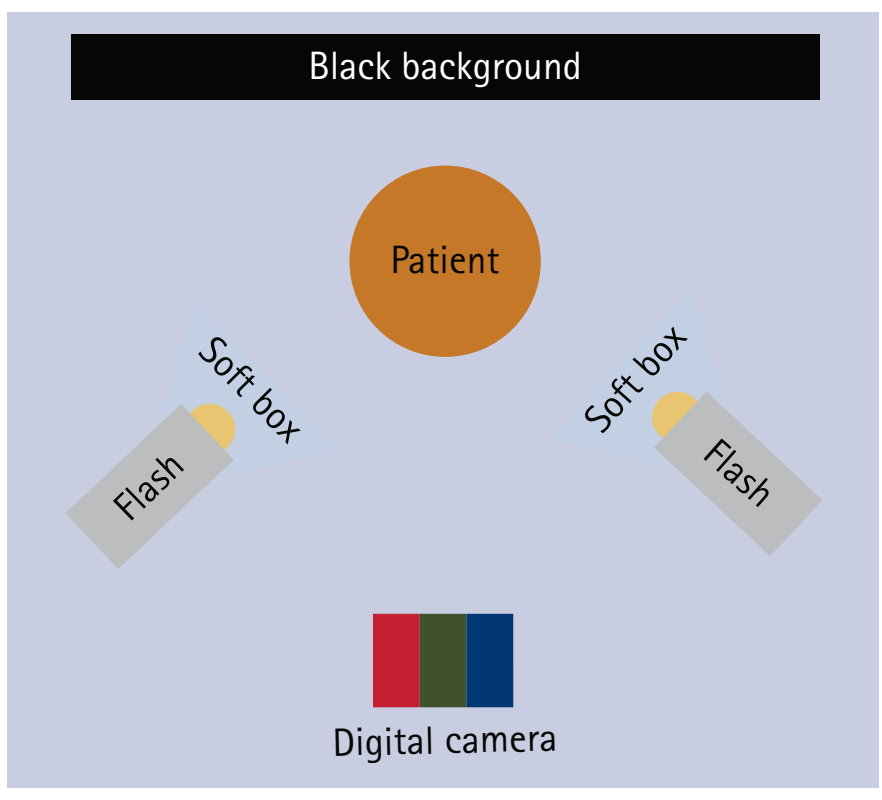

Fig. 10 Studio set-up 2: black background, two flashes

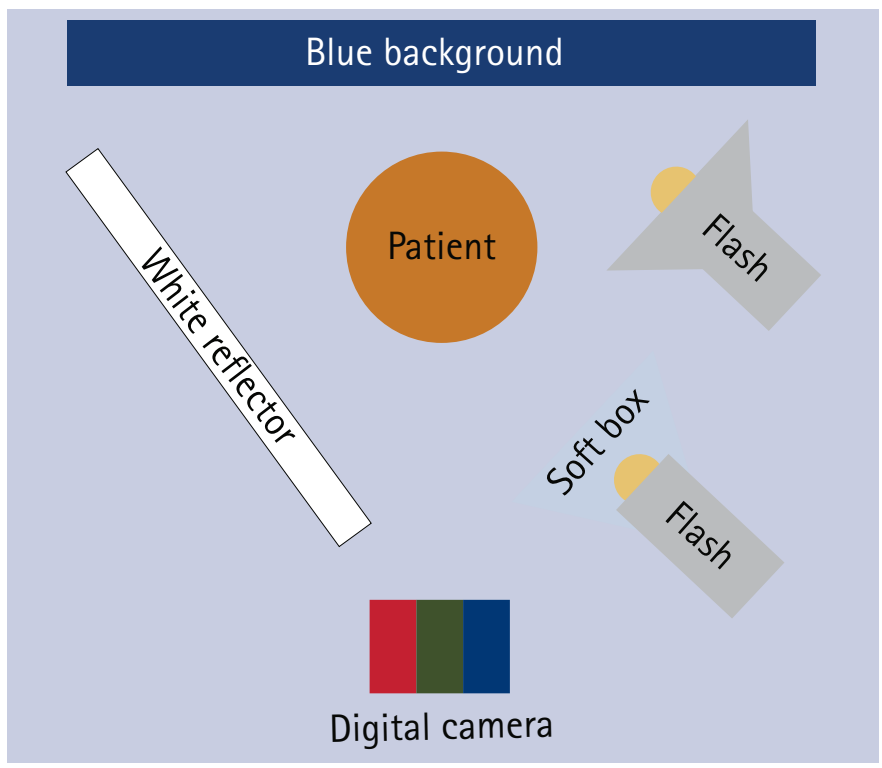

Fig. 12 Studio set-up 3: coloured background, two flashes, one reflector

\section{Black background}

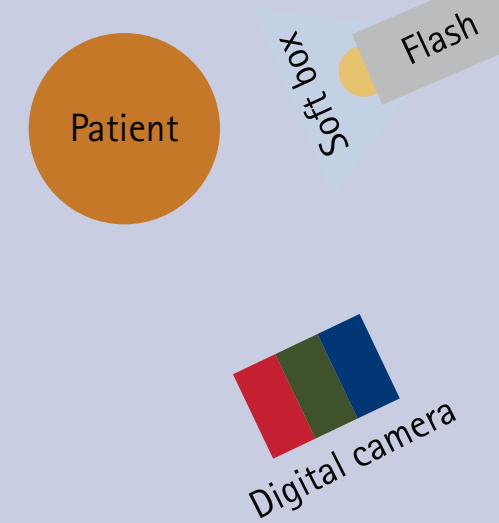

Fig. 14 Studio set-up 4: black background, one flash

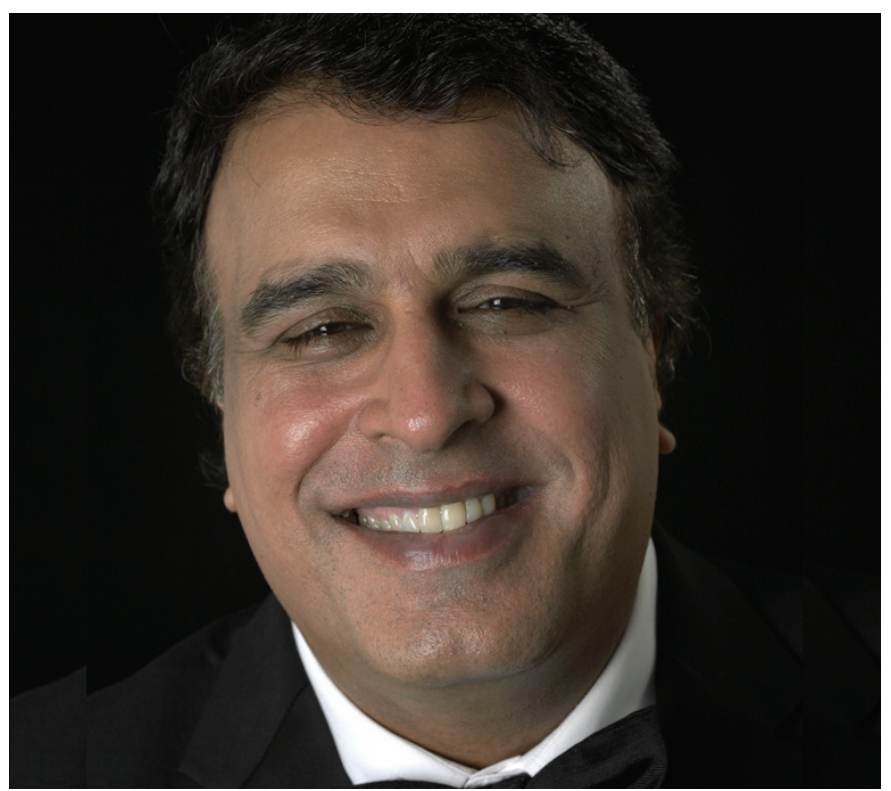

Fig. 11 Image using set-up shown in Figure 10

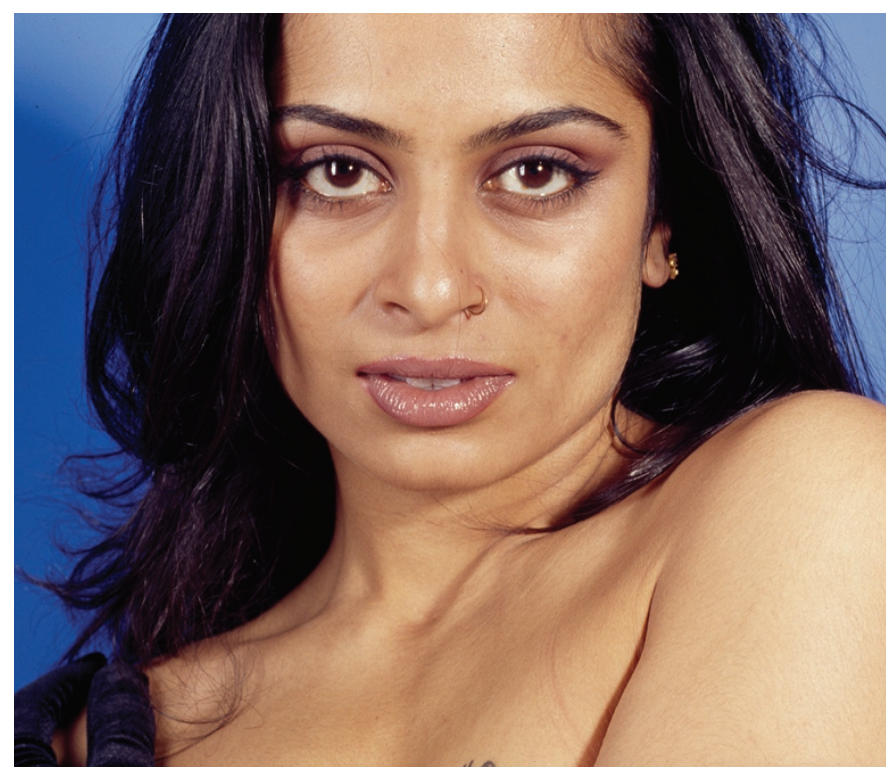

Fig. 13 Image using set-up shown in Figure 12

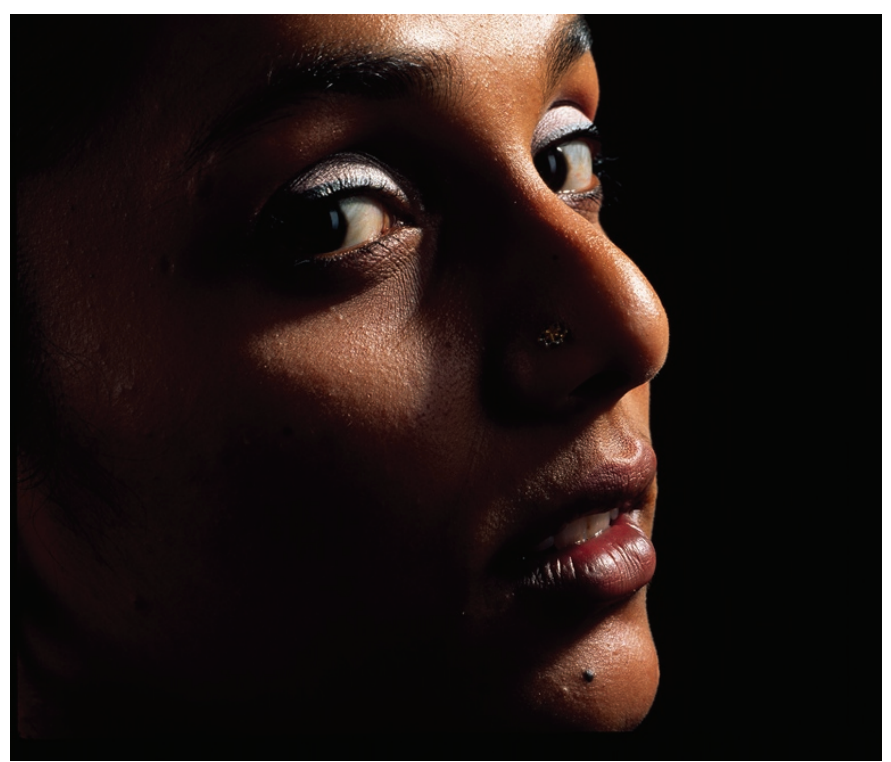

Fig. 15 Image using set-up shown in Figure 14 


\section{PRACTICE}

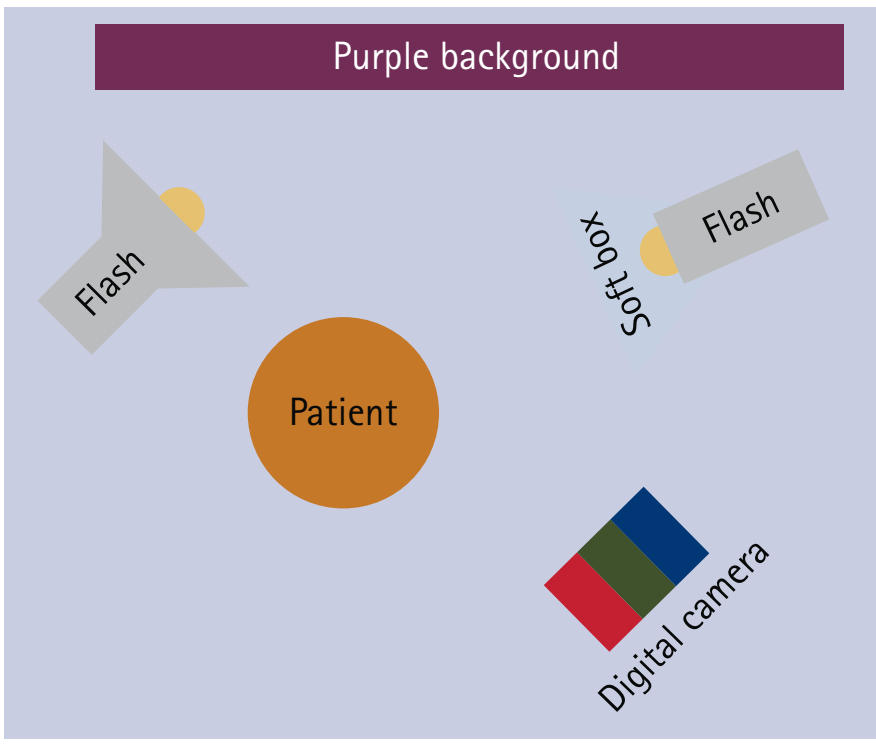

Fig. 16 Studio set-up 5: coloured background, two flashes

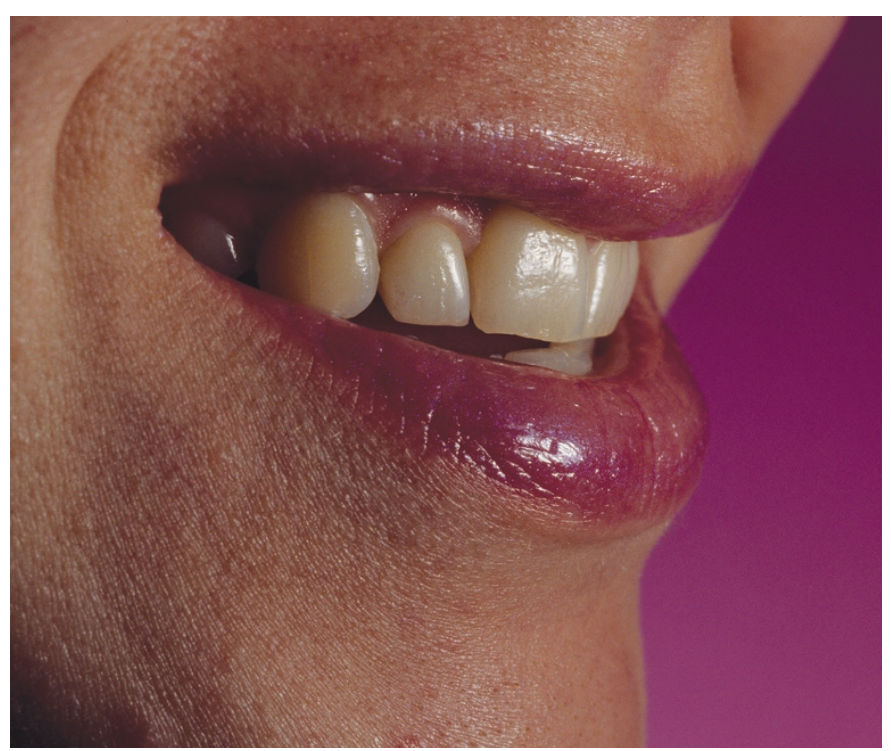

Fig. 17 Image using set-up shown in Figure 16

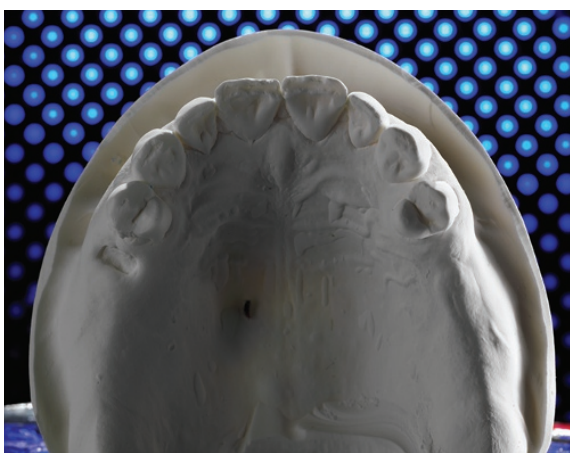

Fig. 18 Pre-operative cast

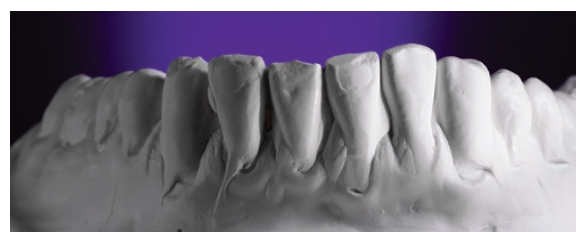

Fig. 21 Pre-operative cast

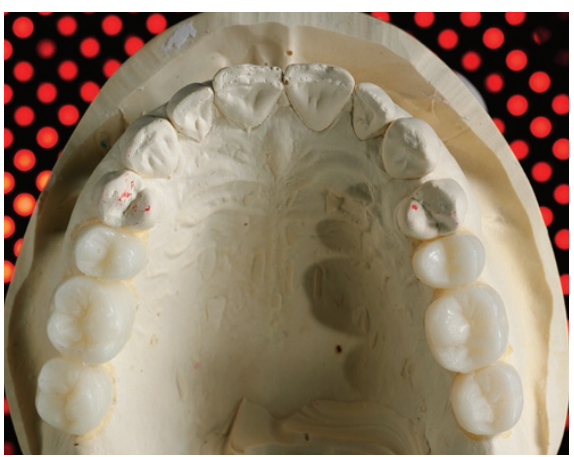

Fig. 19 Wax-up of poster quadrants

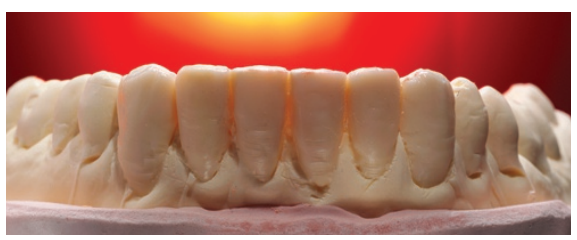

Fig. 22 Wax-up for proposed veneers

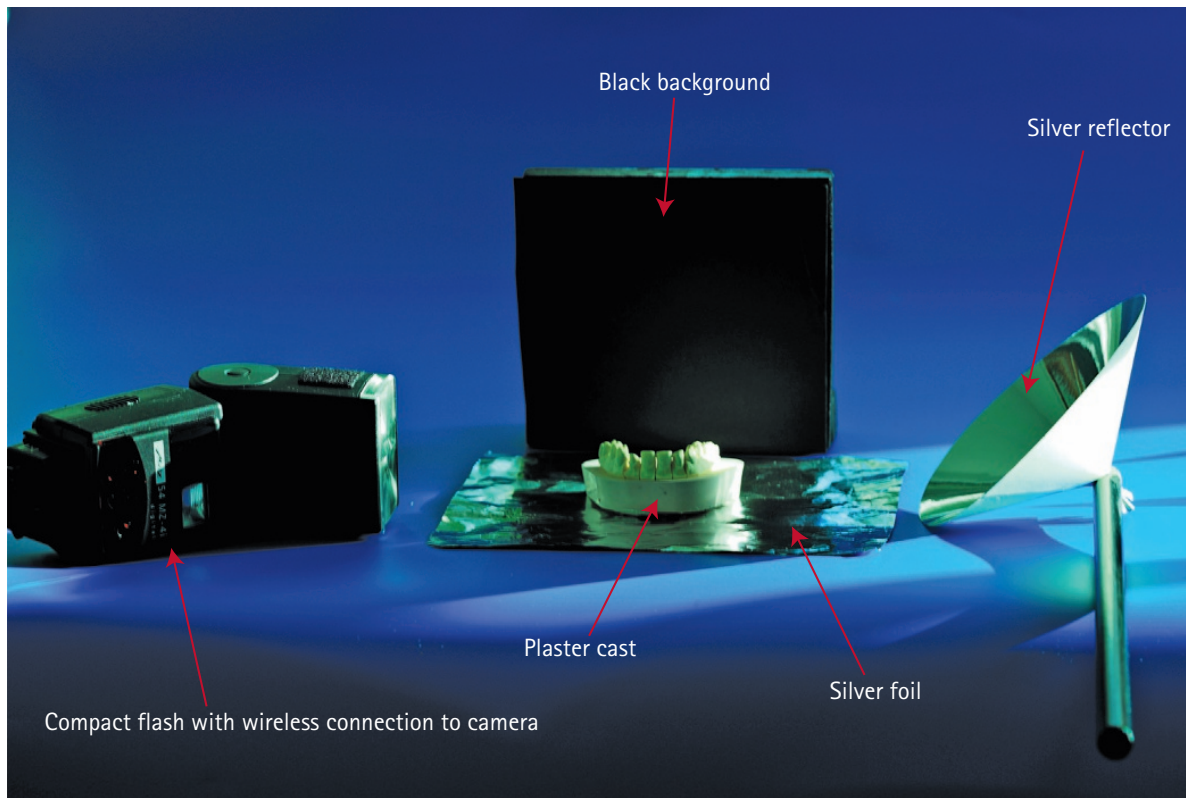

Fig. 24 Laboratory set-up 1: black background, one flash, one reflector

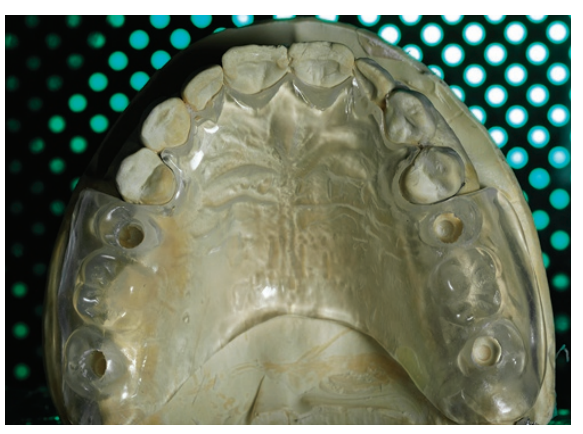

Fig. 20 Surgical stent with drill guides for implant location

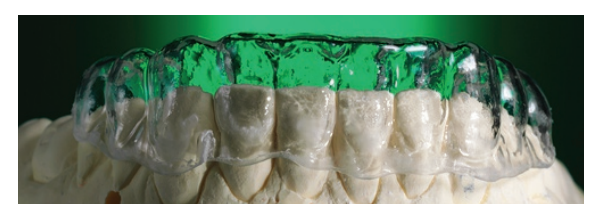

Fig. 23 Vacuum stent for fabricating chairside temporary veneers

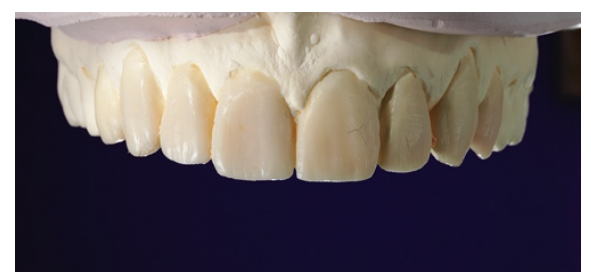

Fig. 25 Image using set-up shown in Figure 24

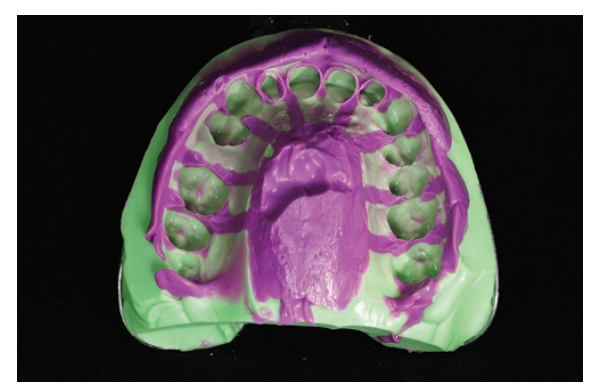

Fig. 26 Impression photographed using set-up shown in Figure 24 
professional still life table is used for supporting the laboratory items. Beside the fact that small objects instead of the face are being photographed, the lighting, backgrounds, etc are very similar. Once again, testing with a grey card is recommended for ascertaining correct exposure and white balance calibration.

The second option is to use the cameramounted flashes that are used for intraoral photography. Since the objects to be photographed are relatively small, the light intensity from these compact flashes is adequate for illumination. An important point to remember when purchasing compact flashes is that they should be detachable from the camera for ease of manoeuvrability and greater versatility for different illumination. Another useful facility is having wireless connection between the camera and flashes that avoids infuriating cables. If the flashes are not detachable, a standard bi-lateral set-up can be used, but will result in unwanted shadows behind plaster models with coloured backgrounds (similar to facial pictures, see Fig. 7). The only way to circumvent this nuisance is using a black background.

The plaster cast is placed onto foil or reflective surface to illuminate the cast from below and eliminate shadows. If a coloured background is chosen, one flash is directed to illuminate the latter and to optically separate the plaster model from the background. If a black background is used, no background illumination is necessary. For uniform illumination, one flash is placed $45^{\circ}$ to the side while the opposite side has a reflector, again at $45^{\circ}$ to bounce light back onto the plaster model. However, for achieving creative lighting effects, the flashes are placed and aligned in different positions. Of course any of the above flash positions can be combined with reflectors of different colours and textures to achieve different and interesting results. A little experimentation and patience can yield unique and striking effects. The basic set-ups are as follows.

\section{Laboratory set-up 1 : black back- ground, one flash and one reflector}

This is a standard set-up with a black background, one flash and a silver reflector on the opposite side. Both the flash and reflector can be placed in

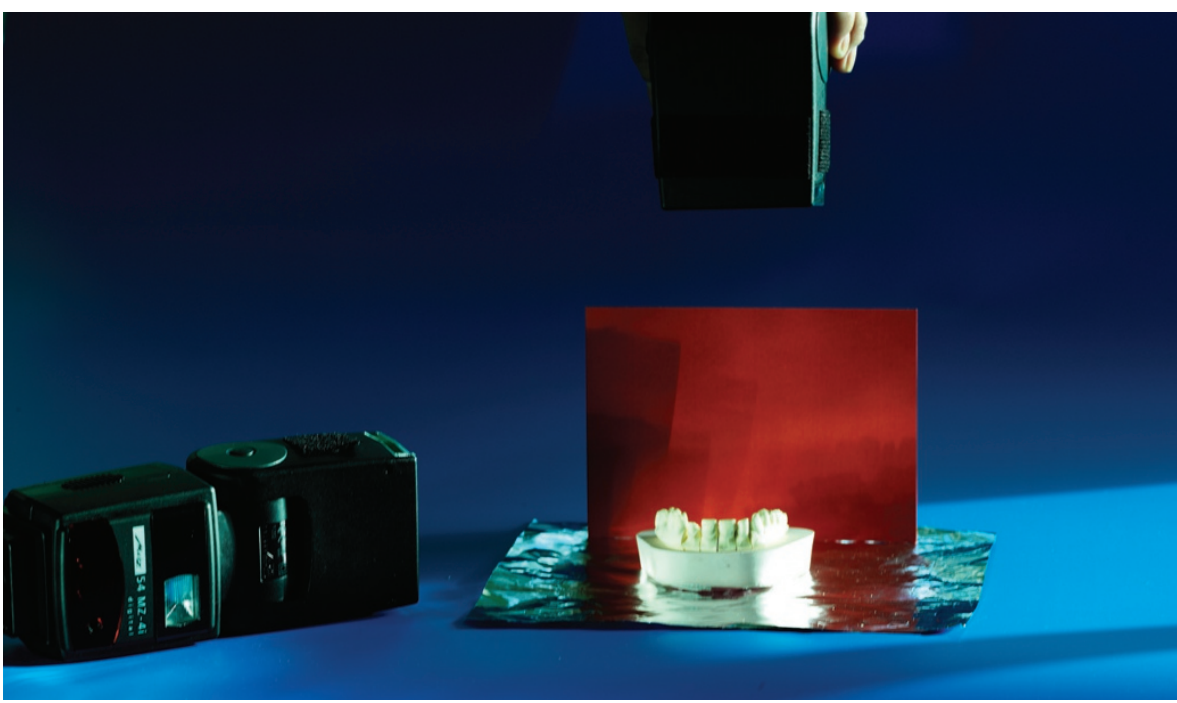

Fig. 27 Laboratory set-up 2: coloured background, two flashes

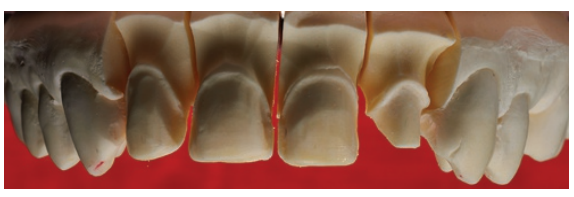

Fig. 28 Image using set-up shown in Figure 27

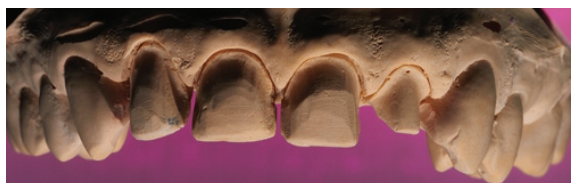

Fig. 29 Another image using set-up shown in Figure 27

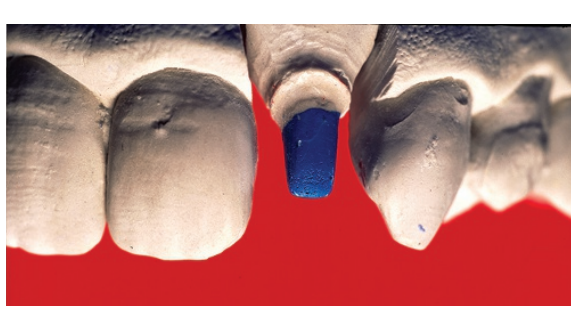

Fig. 30 Clearly visible crown margins of left lateral incisor using the set-up shown in Figure 27

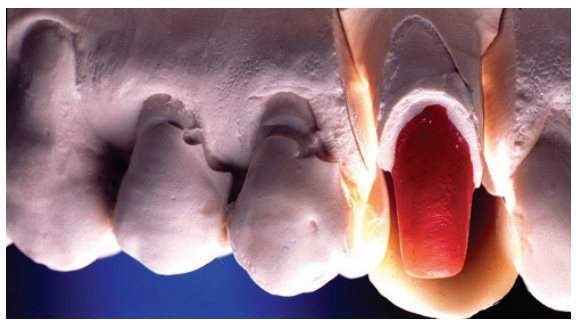

Fig. 31 Clearly discernible crown margins of crown of maxillary canine using the set-up shown in Figure 27 (the ceramic crown has been superimposed onto the tooth preparation)

any position to achieve different illumination effects (Figs 24-25). This arrangement is also used to photograph impressions (Fig. 26).

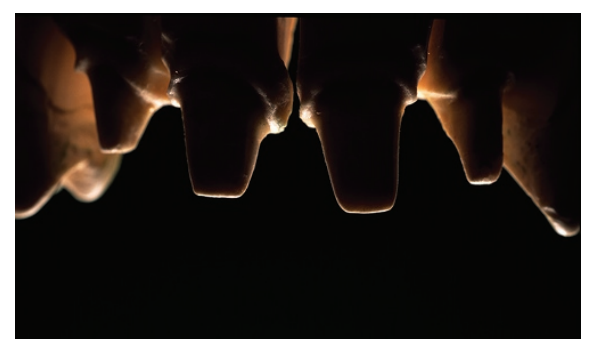

Fig. 32 Angling the flash behind and above the plaster cast highlights preparation outlines using the set-up shown in Figure 27

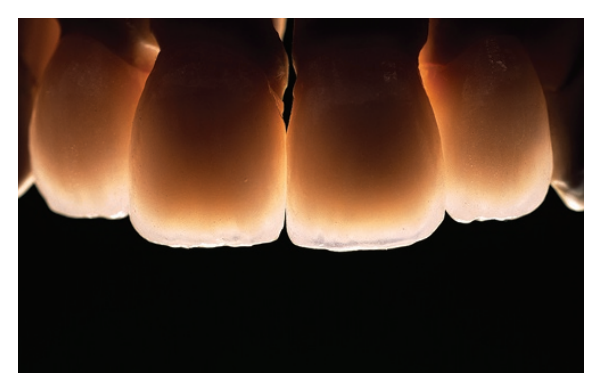

Fig. 33 Trans-illumination allows visualisation of porcelain layer build-ups and incisal translucency

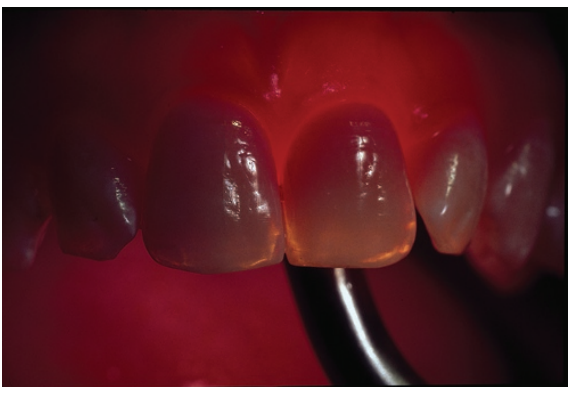

Fig. 34 Fibre-optic trans-illumination allows visualisation of natural enamel opalescence

\section{Laboratory set-up 2: coloured background, two flashes (top)}

If a coloured background is used it must be illuminated separately. The first flash is 


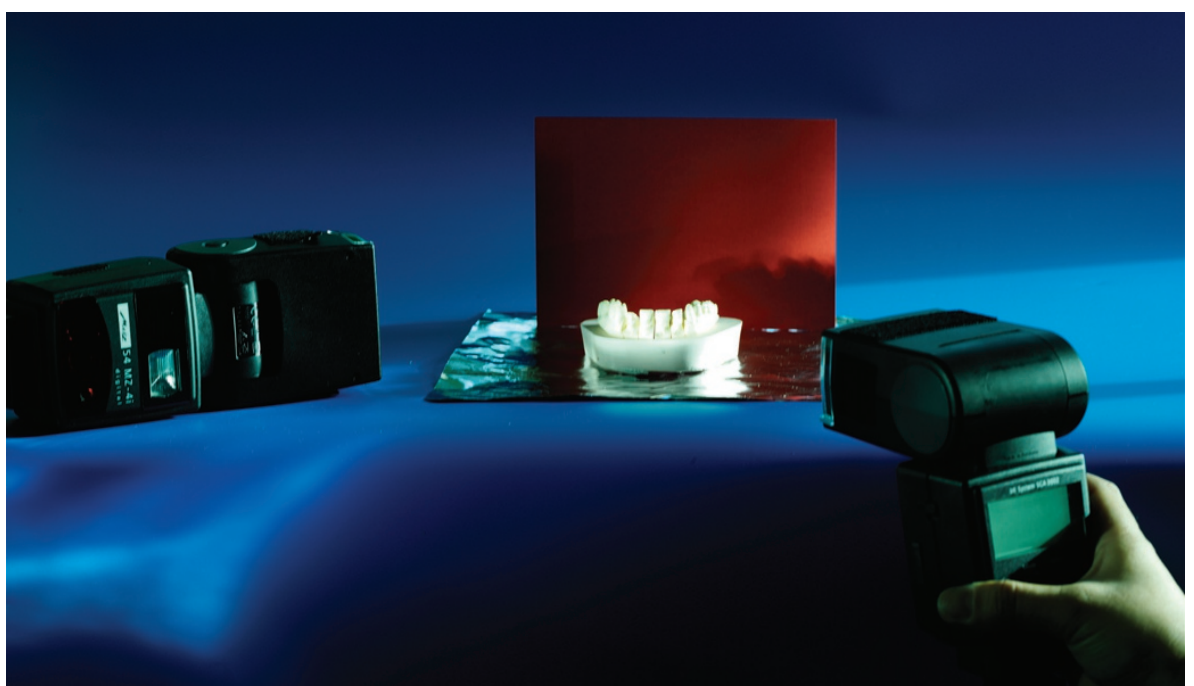

Fig. 35 Laboratory set-up 4: placing flash in front of model

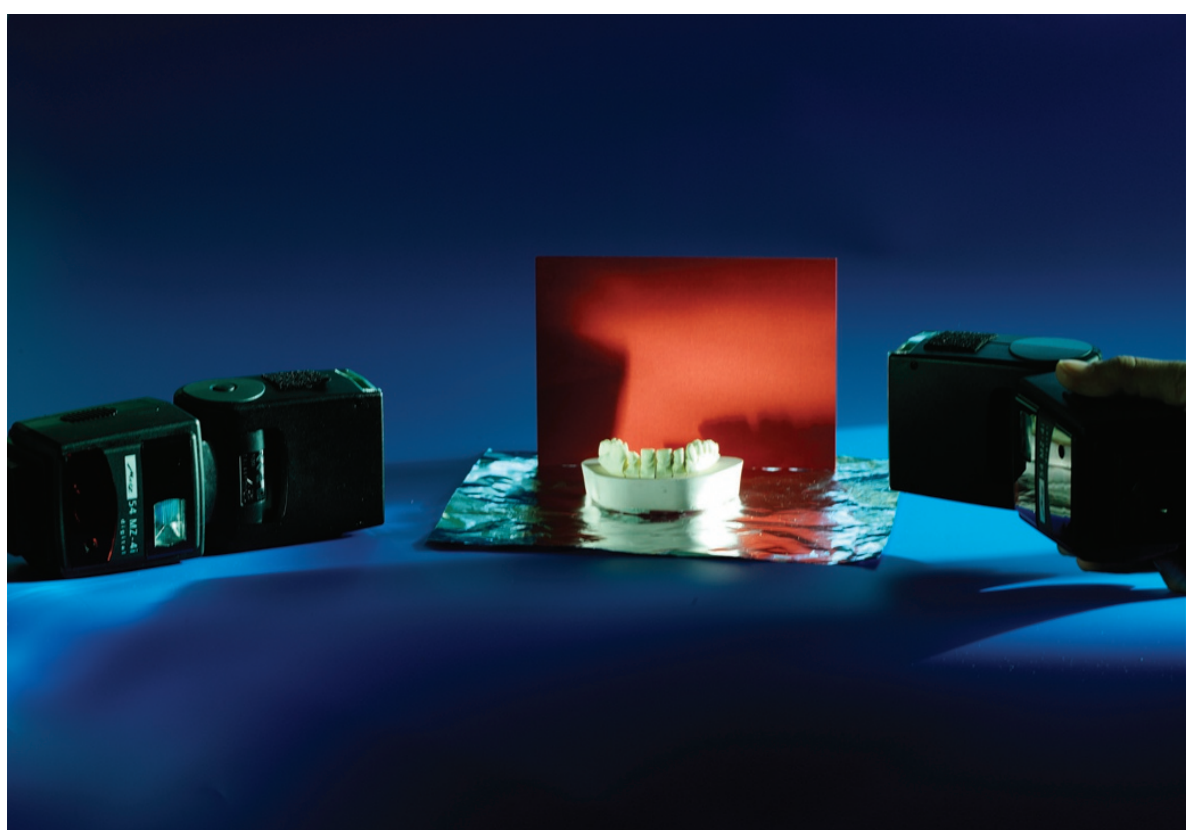

Fig. 37 Laboratory set-up 5: flash placed to right side of plaster cast

aimed at the red card, while the second is freely moved from above to illuminate the plaster cast. This arrangement is useful for capturing crown preparation margins and varying the angle of the flash illuminating the model will revealed the salient features (Figs 27-32). Another useful effect is trans-illuminating all-ceramic restorations to visualise internal stains and porcelain layers (Fig. 33).

\section{Laboratory Set-up 3: coloured background, two flashes (behind)}

The set-up is identical to that described above, but the ambient light needs to be reduced or the picture taken in total darkness. A single flash is placed above and behind the ceramic restoration(s), or a

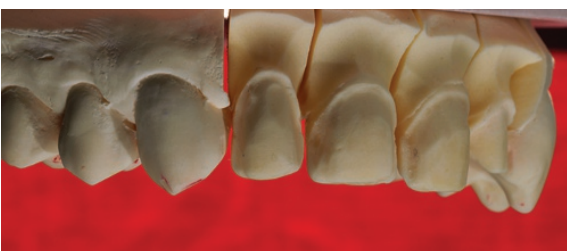

Fig. 36 Image using set-up shown in Figure 35

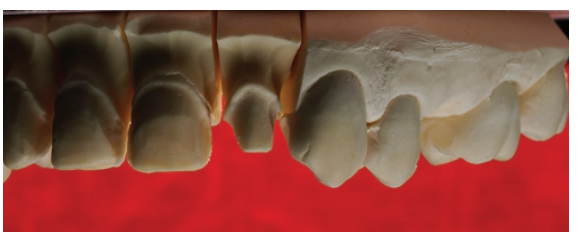

Fig. 38 Image using set-up shown in Figure 37

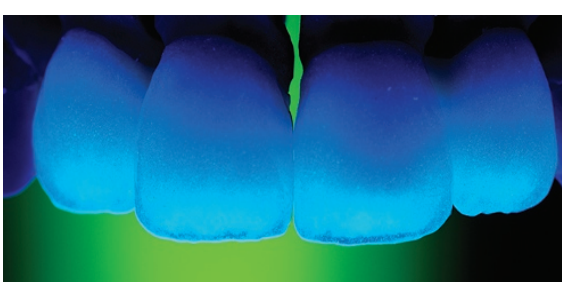

Fig. 39 UV illumination allows checking for porosity or fractures within all-ceramic restorations

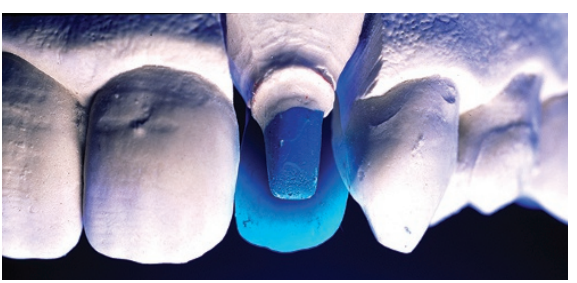

Fig. 40 Photograph with UV illumination of crown on left lateral incisor (the crown has been superimposed onto the tooth preparation)

\section{Laboratory set-up 5: coloured} background, two flashes (one side)

fibre-optic light tip is placed behind the restoration, ensuring that the tip is not visible in the viewfinder. Fibre-optic cables of varying diameters and length are available from most photographic suppliers. Angling a fibre-optic tip can create striking results and reveal features such as translucencies, mamelons, stains and cracks within artificial prostheses. Fibre-optic cables are also an excellent method of showing opalescence of natural enamel and enamel porcelains (Fig. 34).

\section{Laboratory set-up 4: coloured background, two flashes (front)}

Placing the second flash in front of the cast (Fig. 35) produces the lighting effect shown in Figure 36.
Another variation is moving the flash either to the right or the left to illuminate one side while creating shadows on the other, which conveys depth and dimensionality (Figs 37-38).

\section{Ultra-violet illumination}

Finally, ultra-violet illumination (UV) shows internal fluorescence of the various porcelain layers within an all-ceramic restoration. Photographing with UV light is also useful for checking porosity or fractures within all-ceramic units, which can be detrimental to the longevity of the restoration in the oral cavity (Figs 39-40).

\footnotetext{
1. Ahmed I. Digital dental photography. Part 6:
} Camera settings. Br Dent J 2009; 207: 63-69. 